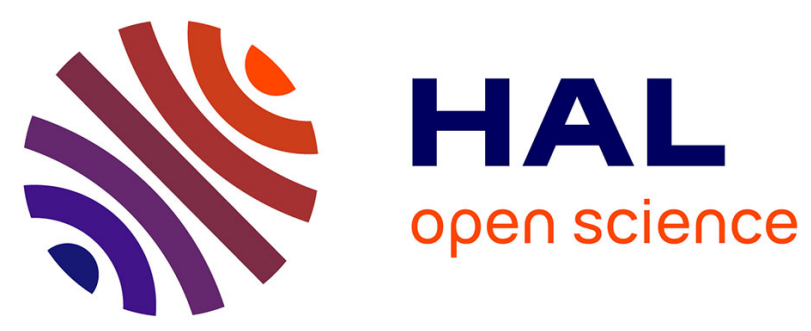

\title{
Uncertainty and sensitivity analysis of laboratory test simulations using an elastoplastic model
} Fernando Lopez-caballero, Arézou Modaressi-Farahmand Razavi

\section{To cite this version:}

Fernando Lopez-caballero, Arézou Modaressi-Farahmand Razavi. Uncertainty and sensitivity analysis of laboratory test simulations using an elastoplastic model. 7th European Conference on Numerical Methods in Geotechnical Engineering, Jun 2010, Trondheim, Norway. hal-03112810

\section{HAL Id: hal-03112810 https://hal.science/hal-03112810}

Submitted on 17 Jan 2021

HAL is a multi-disciplinary open access archive for the deposit and dissemination of scientific research documents, whether they are published or not. The documents may come from teaching and research institutions in France or abroad, or from public or private research centers.
L'archive ouverte pluridisciplinaire HAL, est destinée au dépôt et à la diffusion de documents scientifiques de niveau recherche, publiés ou non, émanant des établissements d'enseignement et de recherche français ou étrangers, des laboratoires publics ou privés. 


\title{
Uncertainty and sensitivity analysis of laboratory test simulations using an elastoplastic model
}

\author{
Fernando Lopez-Caballero \& Arezou Modaressi-Farahmand-Razavi \\ Laboratoire MSS-Mat CNRS UMR 8579, Ecole Centrale Paris, France
}

\begin{abstract}
The focus of the present paper is on Monte Carlo approaches to uncertainty and sensitivity analysis of laboratory test simulations. The soil behaviour is simulated using an elastoplastic multi-mechanism model. The Fourier amplitude sensitivity test (FAST) method is performed in order to assess the influence of input parameters on the response of the model following several loading paths. According to the sensitivity indices derived by FAST method, each parameter has an important role following both the loading path and the strain range.
\end{abstract}

\section{INTRODUCTION}

The role played by the soil behaviour is fundamental in geotechnical analyses. The factors that constitute the essential elements of a well modelling besides a powerful method to solve the boundary value problem are: necessary data, an appropriate constitutive model and adequate model parameters. The necessary data are obtained by laboratory tests or/and in-situ measurements. In the case where they are not available, correlations can be used.

In some geotechnical problems, the use of models based on the elastoplasticity theory to represent the complex behaviour of soils is always suitable as they represent a rational mechanical process (Pande \& Pietruszczak 1986). Unfortunately, one of the obstacles in using such kind of models is the difficulty in identifying their parameters added to the lack of knowledge of soil properties. Thus, the uncertainty associated with their parameter determination should be considered simultaneously to the variability of geotechnical data.

A good understanding of the simulation of soil behaviour could be addressed through local or global sensitivity analyses, that is, the assessment of the impact of individual input parameters or sets of input parameters on the response of the model.

In this paper, a probabilistic analysis is performed in order to illustrate the effect of uncertainty in both soil properties and model parameters on the responses of simulated soil laboratory tests. These analyses are performed for modelling both monotonic and cyclic tests. A number of sensitivity indices based on Monte
Carlo simulation techniques (e.g. Fourier amplitude sensitivity test, FAST) will be presented.

The elastoplastic multi-mechanism model developed at École Centrale Paris, know as ECP model, (Aubry et al. 1982, Hujeux 1985) is used to represent the soil behaviour. This model can take into account the soil behaviour in a large range of deformations. Thus, the impact of several parameters concerning both the elastic and plastic behaviour of the soil will be studied.

\section{CONSTITUTIVE MODEL}

The ECP's elastoplastic multi-mechanism model is written in terms of effective stress. The representation of all irreversible phenomena is made by four coupled elementary plastic mechanisms : three planestrain deviatoric plastic deformation mechanisms in three orthogonal planes and an isotropic one.

The model uses a Coulomb type failure criterion and the critical state concept. The evolution of hardening is based on the plastic strain (deviatoric and volumetric strain for the deviatoric mechanisms and volumetric strain for the isotropic one). To take into account the cyclic behaviour a kinematical hardening based on the state variables at the last load reversal is used.

The model is written in the framework of the incremental plasticity, which assumes the decomposition of the total strain increment in two, elastic and plastic, parts. In what follows, a brief overview of the essential aspects of the constitutive model for primary loading paths is given. 
The elastic part is supposed to obey a non-linear elasticity behaviour, where the bulk $(K)$ and the shear $(G)$ moduli are functions of the mean effective stress $\left(p^{\prime}\right)$ :

$$
K=K_{\text {ref }}\left(\frac{p^{\prime}}{p_{\text {ref }}}\right)^{n_{e}} \text { and } G=G_{\text {ref }}\left(\frac{p^{\prime}}{p_{\text {ref }}}\right)^{n_{e}}
$$

where $K_{r e f}$ and $G_{r e f}$ are the bulk and shear moduli measured at the mean reference pressure $\left(p_{r e f}\right)$ and $n_{e}$ is the degree of non-linearity.

Adopting the soil mechanics sign convention (compression positive), the deviatoric primary yield surface of the $k$ plane is given by:

$$
f_{k}\left(\sigma, \varepsilon_{v}^{p}, r_{k}\right)=q_{k}-\sin \phi_{p p}^{\prime} \cdot p_{k}^{\prime} \cdot F_{k} \cdot r_{k}
$$

with:

$$
\begin{aligned}
& F_{k}=1-b \ln \left(\frac{p_{k}^{\prime}}{p_{c}}\right) \\
& p_{c}=p_{c o} \exp \left(\beta \varepsilon_{v}^{p}\right)
\end{aligned}
$$

where, $\phi_{p p}^{\prime}$ is the friction angle at the critical state. The parameter $b$ controls the form of the yield surface in the $\left(p^{\prime}, q\right)$ plane and varies from $b=0$ to 1 passing from a Coulomb type surface to a Cam-Clay type one. $\beta$ is the plasticity compression modulus and $p_{c o}$ represents the critical state stress corresponding to the initial voids ratio.

The internal variable $r_{k}$, called degree of mobilized friction, is associated with the plastic deviatoric strain. This variable introduces the effect of shear hardening of the soil and permits the decomposition of the behaviour domain into pseudo-elastic, hysteretic and mobilized domains, its evolution law is given by:

$$
\dot{r}_{k}=\dot{\lambda}_{k}^{p} \frac{\left(1-r_{k}\right)^{2}}{a}
$$

where $\dot{\lambda}_{k}^{p}$ is the plastic multiplier of $k$ mechanism.

$$
a=a_{1}+\left(a_{2}-a_{1}\right) \alpha_{k}\left(r_{k}\right)
$$

where :

$$
\begin{array}{ll}
\alpha_{k}=0 & \text { if } r_{k}^{\text {elas }}<r_{k}<r_{k}^{\text {hys }} \\
\alpha_{k}=\left(\frac{r_{k}-r_{k}^{\text {hys }}}{r_{k}^{\text {mob }}-r_{k}^{\text {hys }}}\right)^{m} & \text { if } r_{k}^{\text {hys }}<r_{k}<r_{k}^{\text {mob }} \\
\alpha_{k}=1 & \text { if } r_{k}^{\text {mob }}<r_{k}<1
\end{array}
$$

where $a_{1}, a_{2}$ and $m$ are model parameters and $r^{\text {hys }}$ and $r^{m o b}$ designate the extend of the domain where hysteresis degradation occurs. The isotropic yield surface is assumed to be :

$$
f_{\text {iso }}=\left|p^{\prime}\right|-d p_{c} r_{i s o}
$$

with :

$$
\dot{r}_{i s o}=\dot{\varepsilon}_{v_{i s o}}^{p} \frac{\left(1-r_{i s o}\right)^{2}}{c_{m o n} \frac{p_{c}}{p_{r e f}}}
$$

where $d$ is a model parameter representing the distance between the isotropic consolidation line and the critical state line in the $\left(e-\ln p^{\prime}\right)$ plane and $c_{m o n}$ controls the volumetric hardening.

In the model, an associated flow rule in the deviatoric plane $(k)$ is assumed, and the Roscoe's dilatancy rule (Roscoe et al. 1958) is used to obtain the increment of the volumetric plastic strain of each deviatoric mechanism so that :

$$
\dot{\varepsilon}_{v k}^{p}=\dot{\lambda}_{k}^{p} \cdot \alpha_{\psi} \cdot \alpha_{k}\left(r_{k}\right)\left(\sin \psi-\frac{q_{k}}{p_{k}^{\prime}}\right)
$$

$\psi$ is the characteristic angle and $\alpha_{\psi}$ a constant parameter.

The parameters of the model concern both the elastic and plastic behaviour of the soil. We propose to classify the model parameters with respect to their estimation method. In this scope, the parameters used in the elastoplastic model are separated in two categories: those that can be directly measured from either in-situ or laboratory test results and those which, cannot be directly measured (Table 1).

Table 1. Classification of the Elastoplastic model parameters

\begin{tabular}{lcc}
\cline { 2 - 3 } & $\begin{array}{c}\text { Directly } \\
\text { measured }\end{array}$ & $\begin{array}{c}\text { Not-Directly } \\
\text { measured }\end{array}$ \\
\hline Elastic & $\begin{array}{c}K_{\text {ref }}, G_{\text {ref }} \\
n_{e}, p_{\text {ref }}\end{array}$ \\
Critical State & $\phi_{p p}^{\prime}, \beta$ & $b$ \\
and Plasticity & $p_{c o}, d$ & \\
Flow Rule and & $\psi$ & $a_{1}, a_{2}, \alpha_{\psi}$, \\
Isotropic hardening & & $\begin{array}{c}m, c_{m o n} \\
\text { Threshold }\end{array}$ \\
domains & & $\begin{array}{r}r^{\text {ela }}, r^{\text {hys }} \\
r^{\text {mob }}, r_{\text {iso }}^{\text {ela }}\end{array}$ \\
\hline
\end{tabular}

\section{FAST METHOD}

The global sensitivity analysis is a method used in order to decompose the uncertainty in the output of a computational model according to the input sources of uncertainty (Gatelli et al. 2009). In this kind of sensitivity analysis, the space of the input factors is explored within an infinite region (Saltelli et al. 1999).

Fourier amplitude sensitivity test (FAST), (Cukier et al. 1973, Saltelli et al. 1999) is one the most robust 
global sensitivity analysis techniques (Jacques 2005, Helton et al. 2006, Xu \& Gertner 2008, Mara 2009). In this technique, all input parameters are sampled from a periodic function with a different characteristic frequency. Thus, the output model becomes a periodic function. The Fourier spectrum is then calculated on the model output at specific frequencies so as to obtain the first-order sensitivity index $\left(S_{i}\right)$ of each $x_{i}$ parameter.

Let us consider a computer model $Y=$ $f\left(x_{1}, \ldots, x_{p}\right)$, where $p$ is the number of independent input parameters. The parametric curve assigned to each input parameter is defined as:

$$
x_{i}(s)=\frac{1}{2}+\frac{1}{\pi} \arcsin \left(\sin \left(w_{i} \cdot s\right)\right)
$$

with $x_{i}(s) \in[0,1]^{p}$ and $s=2 \cdot \pi \frac{j-1}{N} ; \forall j=1, \ldots, N$. The $Y$ model is then evaluated $N$ times over the sample of size $N$. If the model output $Y$ is expanded with a Fourier series, the marginal variance $(V)$ can be obtained as:

$$
V \simeq 2 \sum_{j=1}^{\infty}\left(A_{j}^{2}+B_{j}^{2}\right)
$$

where $A_{j}$ and $B_{j}$ are the Fourier coefficients defined as:

$$
\begin{aligned}
& A_{j}=\frac{1}{2 \pi} \int_{-\pi}^{\pi} f(\mathrm{x}(\mathrm{s})) \cos (j s) d s \\
& B_{j}=\frac{1}{2 \pi} \int_{-\pi}^{\pi} f(\mathrm{x}(\mathrm{s})) \sin (j s) d s
\end{aligned}
$$

The marginal partial variance of an individual input parameter $\left(V_{i}\right)$ is obtained from the Fourier coefficients $A_{p w_{i}}$ and $B_{p w_{i}}$ at the harmonics of $w_{i}$ as follows:

$$
V_{i}=2 \sum_{p=1}^{\infty}\left(A_{p w_{i}}^{2}+B_{p w_{i}}^{2}\right)
$$

combining equations 12 and 15, the first-order sensitivity index $\left(S_{i}\right)$ of each $x_{i}$ parameter is defined as:

$$
S_{i}=\frac{V_{i}}{V}
$$

Refer to Saltelli et al. (1999) and Xu \& Gertner (2008) among others for further details about the FAST method.

\section{PROBABILISTIC MODELLING OF MATE- RIAL PROPERTIES}

The sensitivity analysis method is illustrated through its application to a loose sand (i.e. a relative density $D_{r}<50 \%$ ) model parameters. The parameters of the model concern both the elastic and plastic behaviour of the soil and they were determined with the methodology explained in Lopez-Caballero et al. (2003, 2007). The behaviour of the sand is studied by

\begin{tabular}{|c|c|c|c|}
\hline \multicolumn{4}{|l|}{ Elasticity } \\
\hline$K_{r e f}[M P a]$ & 628 & $n_{e}$ & 0.5 \\
\hline$G_{r e f}[M P a]$ & 290 & $p_{r e f}[M P a]$ & 1.0 \\
\hline \multicolumn{4}{|c|}{ Critical State and Plasticity } \\
\hline$\phi_{p p}^{\prime}\left[{ }^{\circ}\right]$ & 30 & $d$ & 2.0 \\
\hline$\beta$ & 33 & $b$ & 0.2 \\
\hline$p_{c o}^{\prime}[k P a]$ & 40 & & \\
\hline \multicolumn{4}{|c|}{ Flow Rule and Isotropic Hardening } \\
\hline$\psi\left[^{\circ}\right]$ & 30 & $\alpha_{\psi}$ & 1.0 \\
\hline$a_{1}$ & 0.0001 & $a_{2}$ & 0.005 \\
\hline$c_{m o n}$ & 0.004 & $m$ & 1.5 \\
\hline \multicolumn{4}{|c|}{ Threshold Domains } \\
\hline$r^{e l a}$ & 0.03 & $r^{h y s}$ & 0.04 \\
\hline$r^{m o b}$ & 0.8 & $r_{i s o}^{e l a}$ & 0.02 \\
\hline
\end{tabular}
simulating drained triaxial tests, drained cyclic shear tests and undrained stress controlled cyclic shear tests. All tests are simulated with the same set of parameters. They are summarized in Table 2.

Table 2. ECP model's parameters for simulated sand

In our elastoplastic model, the variability on these laboratory test results is obtained assuming that the following parameters : $K_{r e f}, G_{r e f}, p_{c o}, \beta, \phi_{p p}^{\prime}, \psi, r^{\text {hys }}$, $c_{m o n}$ and $a_{2}$ have a random character, while the other model parameters are held constant. This set of parameters has been chosen because, as recalled before (Section $\S 2$ ), they concern both physical and numerical parameters and both the elastic and plastic behaviour of the soil (Table 1).

It is necessary to remark that in order to keep a Poisson's ratio $(\nu)$ value constant, the model parameter $K_{r e f}$ is assumed perfectly correlated with $G_{r e f}$ and computed using the following relation from the elasticity: $K_{r e f}=\left(2 \cdot G_{r e f} \cdot(1+\nu)\right) /(3 \cdot(1-2 \cdot \nu))$. Regarding $\psi$ parameter, it represents the limit between contracting and dilating behaviours in sands, which is known as the "phase transformation state" (Ishihara 1993). The value of this parameter may be equal or less than $\phi_{p p}^{\prime}$. In this work, it is assumed that $\psi=\phi_{p p}^{\prime}$.

The mean values of random parameters used in the computations are given in Table 2. For the sake of brevity, all random parameters have a coefficient of variation $\left(V_{C}\right)$ equal to $20 \%$ and it is assumed that all of them are characterized statistically by an uniform distribution. Other studies such as the effects of probability distribution type and other variation coefficient values on the model response are not deemed in this paper. They will be considered in further works.

Using the Monte Carlo approach (MCS) and the FAST method described before, it is possible to take into account the variability of random model param- 
eters and thus to generate the uncertainty laboratory test curves.

In the following figures, the mean, the \pm one standard deviation and the range of several test curves determined by MCS are showed. These summarized curves involve 1000 sample computations. An initial confinement pressure $p_{o}^{\prime}=50 k P a$ is used in all simulated tests. Figure 1 shows the response obtained by the model in simulated drained triaxial tests. The response is showed in the $q-\varepsilon_{1}$ and $\varepsilon_{v}-\varepsilon_{1}$ planes.

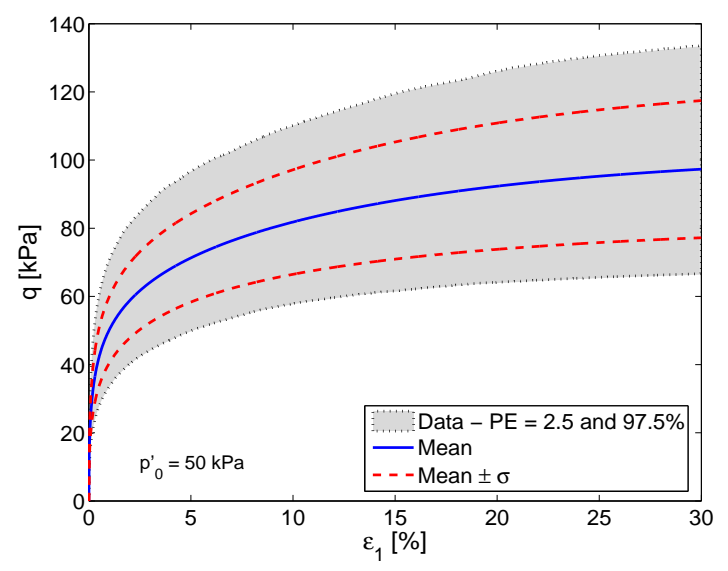

a

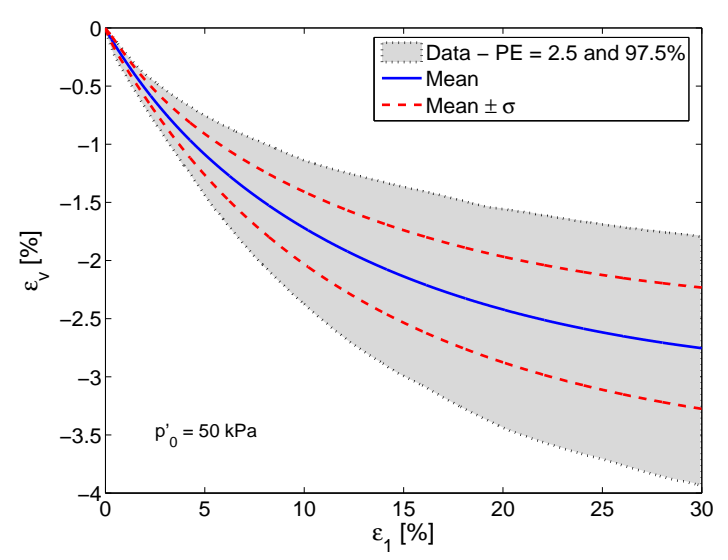

b

Figure 1 . Simulated probabilistic drained triaxial tests a) $q-\varepsilon_{1}$, b) $\varepsilon_{v}-\varepsilon_{1}$.

The uncertainty $G / G_{\max }-\gamma$ curves generated by the simulations are shown in Figure 2a. Finally, for the purpose of assessing the influence of random model parameters on the pore water pressure buildup, a strain controlled cyclic triaxial test has been simulated. Figure $2 \mathrm{~b}$ presents the results for the excess pore water pressure ratio $\left(U^{*}=\Delta p_{w} / p_{0}^{\prime}\right)$ as a function of $\gamma$ after ten loading cycles during the straincontrolled cyclic triaxial test.

Figure 3 illustrates the evolution of coefficient of variation $\left(V_{C}\right)$ as a function of deformation for each simulated test. It is interesting to note that in the case

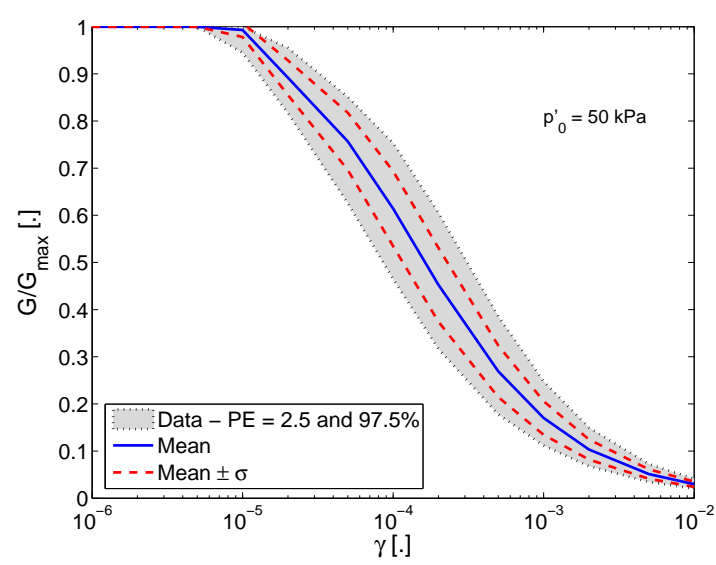

a

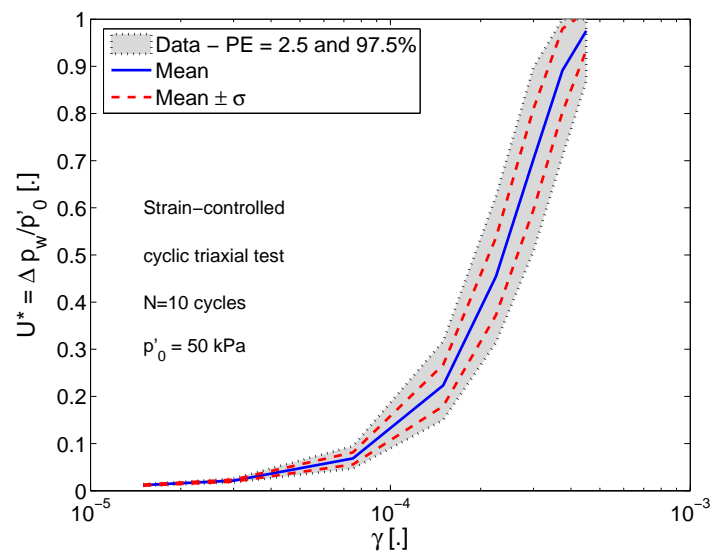

b

Figure 2 . Simulated probabilistic a) $G / G_{\max }-\gamma$ and b) $\Delta p_{w} / p_{o}^{\prime}-\gamma$ curves.

of triaxial test (Fig. 3a), even if all random input parameters have the same $V_{C}$ value, the variation coefficient obtained for $\varepsilon_{v}$ varies from $35 \%$ to $20 \%$ when $\varepsilon_{1}$ increases. This is in contrast with the $V_{C}$ value for $q$, which remains approximatively constant (i.e. $\approx 20 \%$ ).

A similar response is obtained in the case of cyclic tests (Fig. 3). The $V_{C}$ value for $G_{\max }$ increases (from $12 \%$ to $18 \%$ ) when $\gamma$ increases (Fig. 3b). On the other hand, concerning the $V_{C}$ value for $\Delta p_{w}$, it presents a peak for $\gamma \approx 1 \cdot 10^{-4}$. According to Figure $2 b$, this deformation corresponds to the beginning of pore pressure build-up in the test.

\section{GLOBAL SENSITIVITY ANALYSIS}

In this section, so as to assess the influence of the individual input parameters on the output, the first-order indices $\left(S_{i}\right)$ obtained for all simulated laboratory tests are plotted in Figures 4 and 5. Figure 4 a provides the $\varepsilon_{1}$ dependent sensitivity analysis results for uncertain $q$ curves. Accordingly, only the $S_{i}$ of the parameters $p_{c o}, \phi_{p p}^{\prime}$ and $a_{2}$ seem to be nonzero. The outcome shows that among those parameters, for small strains 


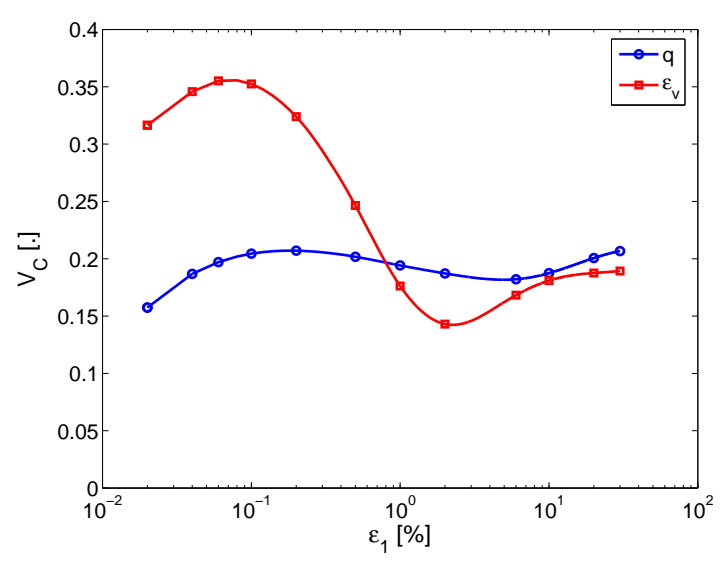

a

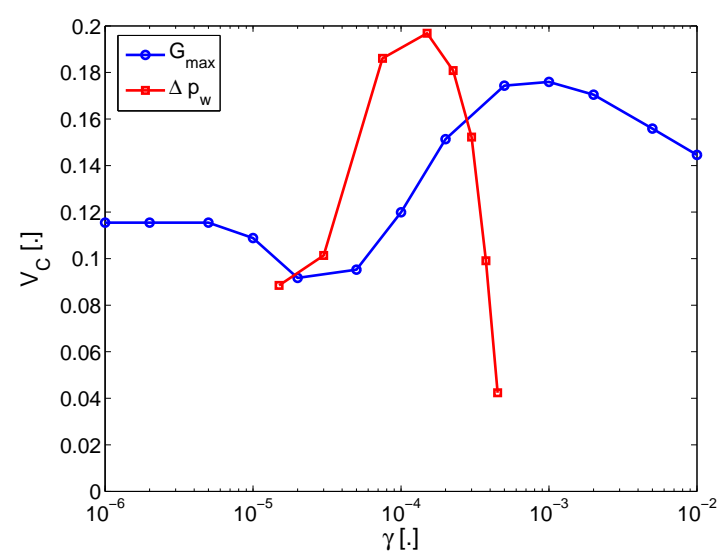

b

Figure 3 . Variation coefficient $V_{C}$ versus deformation $\left(\varepsilon_{1}\right.$ or $\left.\gamma\right)$ for a) $q$ and $\varepsilon_{v}$, b) $G_{\max }$ and $\Delta p_{w}$.

(i.e. $1 \cdot 10^{-2 \%}<\varepsilon_{1}<1 \cdot 10^{-1 \%}$ ) the one with the biggest influence is $a_{2}$, followed by $\phi_{p p}^{\prime}$ and $p_{c o}$. However, as expected, for large strains (i.e. $\varepsilon_{1}>1 \cdot 10 \%$ ) the most influential parameter is $\phi_{p p}^{\prime}$.

Concerning the volumetric strain $\left(\varepsilon_{v}\right)$, it is noted that there is a strong relationship between $\varepsilon_{v}$ and $p_{c o}$ parameter (Fig. 4b) for $\varepsilon_{1}<5 \cdot 10^{-1 \%}$. This is to be expected, because the parameter $p_{c o}$ represents the initial state of the soil. From the same figure, it can be also seen, that for large strains the most influential parameters are $\phi_{p p}^{\prime}$ and $a_{2}$.

Regarding the effect on the shear modulus reduction $G / G_{\max }$ values, Figure 5a illustrates the evolution of $S_{i}$ index as a function of shear strain $(\gamma)$. This shows that $p_{c o}$ parameter has a far smaller role in the $G / G_{\max }$ values. In fact, the model response is controlled by $G_{r e f}$ at small shear strains and both $a_{2}$ and $\phi_{p p}^{\prime}$ for largest $\gamma$ values.

Finally, the resulting $S_{i}$ index values between model parameters and the pore water pressure buildup $\left(\Delta p_{w}\right)$ variable can be seen in Figure 5b. It is interesting to note that for $\gamma$ values between $1 \cdot 10^{-5}$ and $1 \cdot 10^{-4}$ the most influential parameters are $G_{r e f}$ and

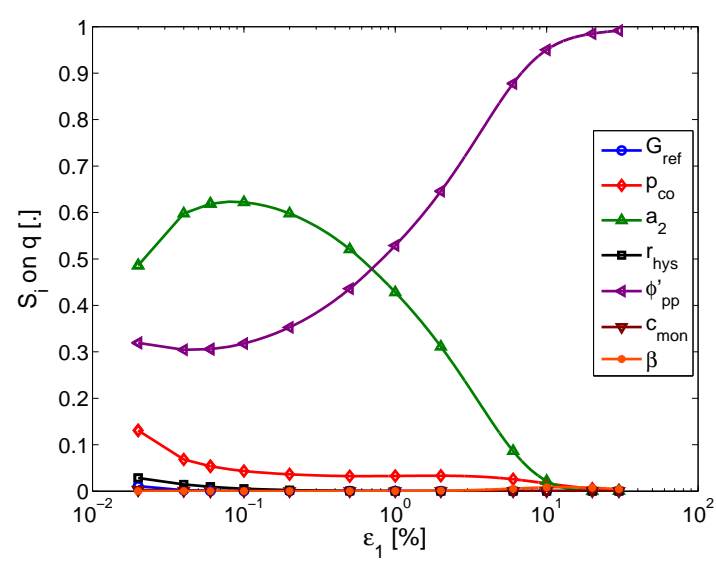

a

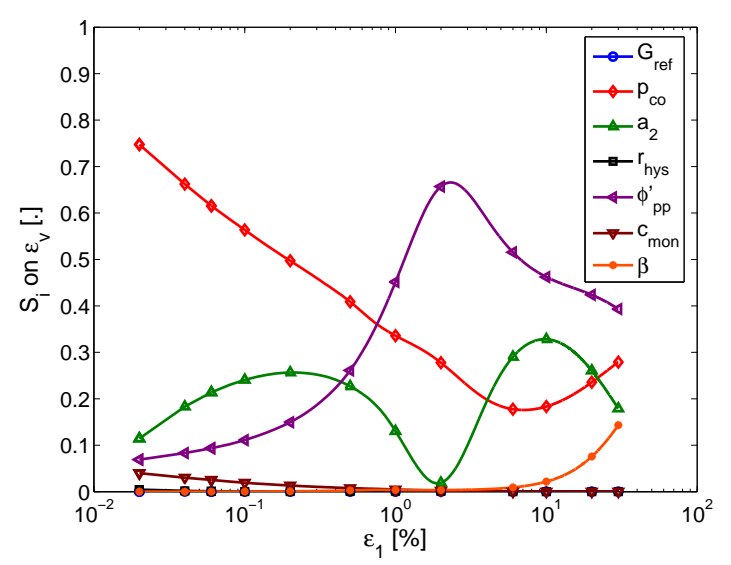

b

Figure 4 . First-order indices $\left(S_{i}\right)$ as a function of $\varepsilon_{1}$ for uncertain : a) $q$ and b) $\varepsilon_{v}$ values. Drained triaxial test.

$r^{h y s}$. Beyond this deformation value, parameters $G_{r e f}$ and $a_{2}$ have the biggest influence.

\section{CONCLUSIONS}

A series of soil mechanics laboratory tests were simulated with the ECP's elastoplastic multi-mechanism model in order to understand the behaviour of the model and to assess how different parameters of the model interplay. In this work a technique for global sensitivity analysis is used to illustrate the effect of each parameter following a particular loading path.

The main conclusions drawn from this study are as follows:

1. According to the responses obtained with the model and for the particular case considered in this work (i.e. model parameters and initial state), it can be concluded that the parameters with the biggest influence on the model response are $G_{r e f}, \phi_{p p}^{\prime}$ and $a_{2}$.

2. As expected, the analyses showed that each parameter has an important role following both the 


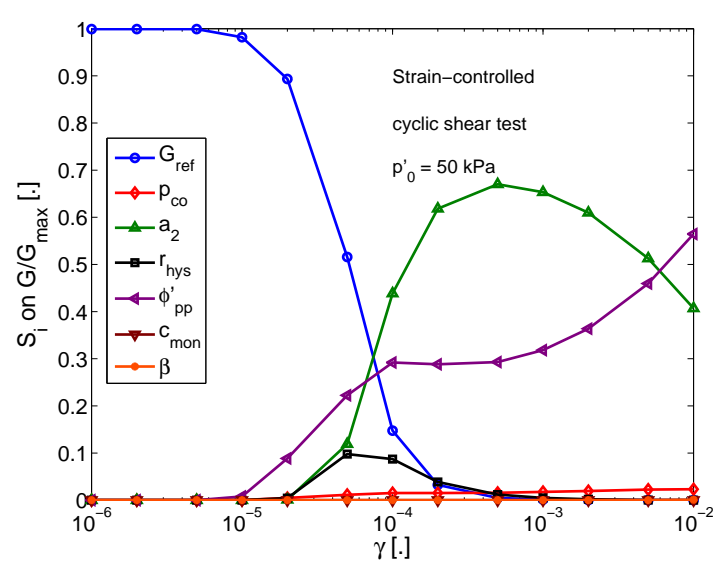

a

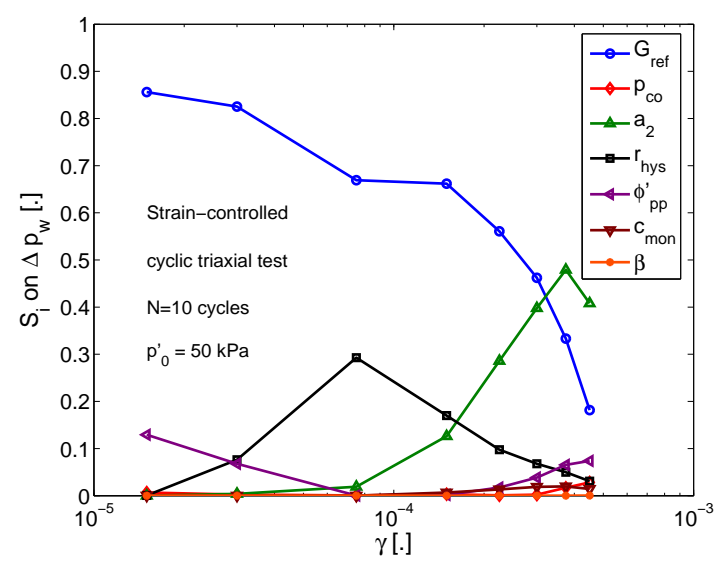

b

Figure 5 . First-order indices $\left(S_{i}\right)$ as a function of $\gamma$ for uncertain : a) $G / G_{\max }$ and b) $\Delta p_{w}$ values. Cyclic shear tests.

loading path and the strain range. However, it is necessary to simulate other loading paths such as consolidation test, so as to show the role played by the parameters $\beta$ and $c_{m o n}$ among others.

3. Further works are needed in order to assess the influence of several probability distribution types for each input parameter on the model response.

\section{ACKNOWLEDGEMENTS}

This study has been done in the framework of the French project ANR-06-CATT-003-01, BELLEPLAINE.

\section{REFERENCES}

Aubry, D., J.-C. Hujeux, F. Lassoudière, \& Y. Meimon 1982. A double memory model with multiple mechanisms for cyclic soil behaviour. In Int. Symp. Num. Mod. Geomech, pp. 3-13. Balkema.

Cukier, R., C. Fortuin, K. Shuler, A. Petschek, \& J. Schaibly 1973. Study of the sensitivity of coupled reaction systems to uncertainties in rate coefficients, I. Theory. Journal Chemical Physics 59: 3873-3878.

Gatelli, D., S. Kucherenko, M. Ratto, \& S. Tarantola 2009.
Calculating first-order sensitivity measures: A benchmark of some recent methodologies. Reliability Engineering and System Safety 94(7): 1212-1219.

Helton, J. C., J. D. Johnson, C. J. Sallaberry, \& C. B. Storlie 2006. Survey of sampling-based methods for uncertainty and sensitivity analysis. Reliability Engineering and System Safety 91(9-10): 1175-1209.

Hujeux, J.-C. 1985. Une loi de comportement pour le chargement cyclique des sols. In Génie Parasismique, pp. 278302. V. Davidovici, Presses ENPC, France.

Ishihara, K. 1993. Liquefaction and flow failure during earthquakes. 33rd Rankine lecture. Géotechnique 43(3): 351415.

Jacques, J. 2005. Contributions à l'analyse de sensibilité et à l'analyse discriminante généralisée. Thèse de doctorat, Université Joseph Fourier, France.

Lopez-Caballero, F., A. Modaressi, \& F. Elmi 2003. Identification of an elastoplastic model parameters using laboratory and in-situ tests. In Deformation Characteristics of Geomaterials, pp. 1183-1190. Eds. Di Benedetto et al., A.A. Balkema, ISBN 9058096041.

Lopez-Caballero, F., A. Modaressi-Farahmand-Razavi, \& H. Modaressi 2007. Nonlinear numerical method for earthquake site response analysis I- elastoplastic cyclic model \& parameter identification strategy. Bulletin of Earthquake Engineering 5(3): 303-323.

Mara, T. 2009. Extension of the RBD-FAST method to the computation of global sensitivity indices. Reliability Engineering and System Safety 94(8): 1274-1281.

Pande, G. N. \& S. Pietruszczak 1986. A critical look at constitutive models for soils. In Geomechanical modelling in engineering practice, pp. 369-395. Eds. R. Dungar and J.A. Studer, A.A. Balkema, Rotterdam, The Netherlands.

Roscoe, K. H., A. N. Schofield, \& C. P. Wroth 1958. On the yielding of soils. Géotechnique 8(1): 22-52.

Saltelli, A., S. Tarantola, \& K.-S. Chan 1999. A quantitative model-independent method for global sensitivity analysis of model output. Technometrics 41(1): 39-56.

Xu, C. \& G. Gertner 2008. A general first-order global sensitivity analysis method. Reliability Engineering and System Safety 93(7): 1060-1071. 